\title{
MITIGATING VENTILATION AIR METHANE COST-EFFECTIVELY FROM A COLLIERY IN AUSTRALIA
}

\author{
R. I. Holmes \\ $\mathrm{PhD}$ Candidate, Federation University, Science \& Engineering bldg. Y, Mt Helen, Victoria, 3350 Australia, \\ e-mail: R.Holmes@federation.edu.au
}

Received: 16.02.2016 / Accepted: 10.03.2016 / Revised: 18.05.2016 / Available online: 31.05.2016

DOI: 10.1515/jaes-2016-0005

KEY WORDS: Ventilation Air Methane, Climate Change, Greenhouse Gas, Fugitive Emissions, Mitigation, Global Climate Change

\begin{abstract}
:
Methane has been controlled in collieries in the past only for safety and statutory compliance reasons; however concerns over greenhouse gas emissions mean that this is now changing. About $65 \%$ of greenhouse emissions associated with underground coal mining come from ventilation air methane (VAM). The machinery to mitigate these fugitive emissions once the VAM exits the mine fans is expensive, has safety concerns and is not widely used at present. Consider these factors; more collieries are mining lower seams, methane content increases with depth, VAM mitigation plants are not widely used, most mine emissions are VAM, and widespread concern over greenhouse gases mean that it is desirable to lower VAM emissions now. One solution would be a method to prevent more methane from entering the mine airstream and becoming VAM in the first place. Recently, in a colliery in the Hunter Valley, this mitigation method underwent a 12-month trial, and involved six different measures. Measurements were taken to assess the emissions mitigation which was achieved, and the cost of the works; all the results are detailed herein. A reduction in fugitive emissions of $80,307 \mathrm{t} / \mathrm{CO} 2$-e below that which was projected for the next 12-month period was quantified, at an average cost of $\mathrm{A} \$ 1.28 \mathrm{ct} / \mathrm{CO} 2-\mathrm{e}$. The mitigation measure outlined here represent a first attempt to the author's knowledge, in an operating mine, to lower a collieries' environmental footprint by preventing methane from entering the mine airstream and becoming VAM gas by the deliberate use of mitigation measures.
\end{abstract}

\section{INTRODUCTION}

\subsection{Fugitive Methane Emissions}

Fugitive methane emissions from coal mines are a problem because methane is a strong greenhouse gas and contributes to global warming. According to the latest report by the Intergovernmental Panel on Climate Change (IPCC, AR5; 2014) anthropogenic greenhouse gas emissions are escalating (Figure 1) this rise is a significant factor in the current period of global warming, which can cause climate change.

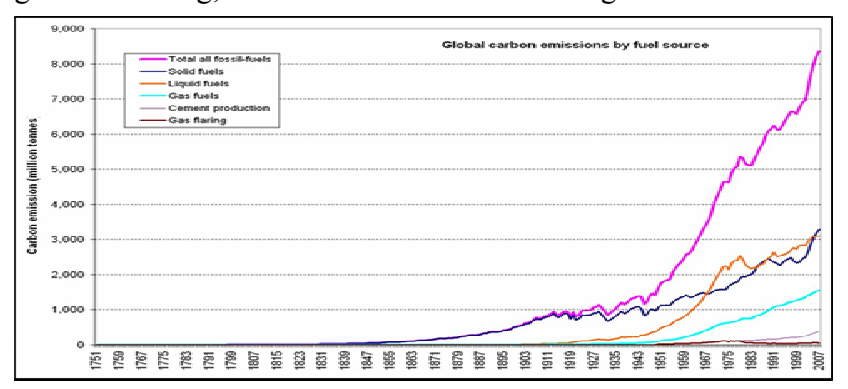

Figure 1. Anthropogenic carbon emissions by fuel source $1751-2007 \mathrm{Mt} / \mathrm{yr}^{-1}$

Climate change which happens relatively suddenly can adversely affect species (Crowley \& North, 1988). Perhaps a greater threat for humanity is to our coastal cities from a sea level rise. A warming climate would melt land ice causing a eustatic sea level rise; and a warming climate would also cause thermal expansion of the oceans, leading to a thermosteric sea level rise. Predictions of total sea level rise that we can expect by 2100 vary widely, but the IPCC's latest report (AR5) projects $28 \mathrm{~cm}-98 \mathrm{c} \mathrm{m}$. Since the start of industrialisation in 1750 we have seen a $0.8^{\circ} \mathrm{C}$ global temperature rise, and global circulation models project about $3^{0} \mathrm{C}$ more in coming centuries if the growth in emissions of greenhouse gases such as carbon dioxide and methane continues on a business as usual path (IPCC, AR5; 2014). Coal mining is Australia's second largest export industry, is a large employer and provides the fuel for most of the country's electrical power generation; however, it is also a large emitter of greenhouse gases. And $65 \%$ of the greenhouse gas emissions from collieries ( $\mathrm{Su}$ et al., 2005) are in the form of uncontrolled ventilation air methane (VAM) fugitive emissions. Methane is a strong greenhouse gas; its greenhouse effect (technically its global warming potential, or GWP) is 21 times that of CO2(Myhre \& Shindell, 2015) (Table 2).

\begin{tabular}{|lr|}
\hline Kyoto Protocol gases & Global warming potentials \\
\hline Carbon dioxide $\left(\mathrm{CO}_{2}\right)$ & 1 \\
\hline Methane $\left(\mathrm{CH}_{4}\right)$ & 21 \\
\hline Nitous oxide $\left(\mathrm{N}_{2} \mathrm{O}\right)$ & 310 \\
\hline Sulphur hexafuonde $\left(\mathrm{SF}_{1}\right)$ & 23900 \\
\hline Hydrofurocarbons $(\mathrm{MFC})$ & $140-11700$ \\
\hline Perfuvorocarbons $(\mathrm{PFCS})$ & $6500-9200$ \\
\hline
\end{tabular}

Table 2. GWP of various gases on 100 year timeframes 


\subsection{Determining GWP}

Determining GWP: it is calculated from the Radiative Forcing Capacity (RF) that is, how much energy is adsorbed by the gas for a unit of time-area. RF is calculated by the formula;

$$
\mathrm{RF}=\sum(\mathrm{n}=1)^{\wedge} 100 \mathrm{Absi}{ }^{*} \mathrm{Fi} /(\text { pathlength*density })
$$

where; $i=10$ inverse centimetres,

Absi $=$ the integrated infrared absorbance of the sample in the interval and

$\mathrm{Fi}=$ the RF for the interval (IPCC).

The combination of high GWP and the low concentration of the VAM gas (typically $0.1 \%-0.8 \%$ ) in the high airflow mine air compounds the problem, because at these low concentrations in this high airflow, it is very difficult to remove (Karakurt et al., 2011). The objective of this work is to demonstrate how, in a recent 12-month VAM gas mitigation trial, fugitive greenhouse gas emissions were significantly reduced in an operating colliery at low cost and without compromising safety.

\subsection{Methane in Collieries}

Coal seam gas (CSG) is usually methane (Sly et al., 1993). Methane is a problem in collieries mainly because it forms an explosive mixture between $5 \%$ and $15 \%$ when in air (McPherson, 2009). Methane is stored in coal by a process called adsorption, and the amount of methane contained in a tonne of coal can range from $2 \mathrm{~m}^{3}$ to $30 \mathrm{~m}^{3}$, the methane is adsorbed into the micro-porous matrix of the coal by intraparticle diffusion (Zhao et al., 2012). When the pressure which is keeping the methane in place reduces, it diffuses into the cleats of the coal. Work by Saghafi et al., (1997) has shown that the methane released from a mine is generally four to seven times that which is contained in the coal seam being mined. The act of long-wall mining a seam relaxes strata up to $170 \mathrm{~m}$ above and up to $60 \mathrm{~m}$ below the seam; most VAM can originate outside the seam being mined, from both above and below (Kissell, 2006). Methane emissions from the coal seam into accessible roadways are generally made safe by rapid dilution using large volumes of fast-flowing air (Figure 3). When diluted into the mine air, methane essentially becomes the fugitive greenhouse gas VAM.

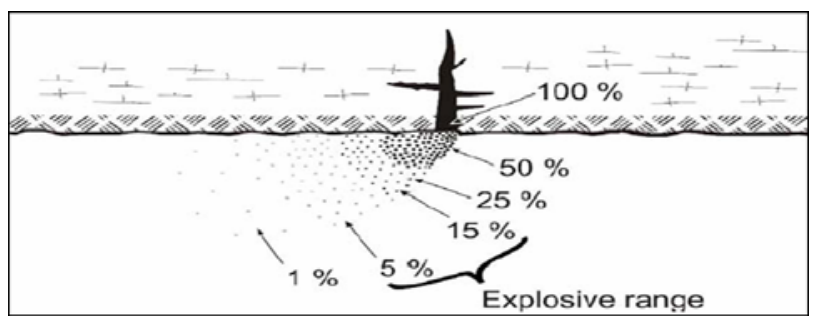

Figure 3. Methane emitted from a coal seam becomes VAM

According to the IPCC, methane is $20.5 \%$ of all man-made greenhouse gas emissions; (Figure 4 ) and $7 \%$ of this methane is fugitive emissions from collieries - mainly in the form of low concentration VAM gas.

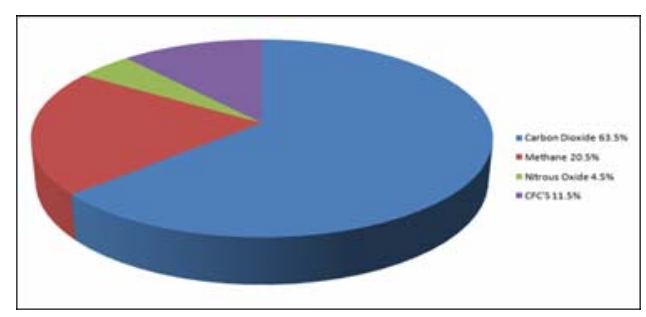

Figure 4. Global sources of greenhouse emissions (IPCC, 2014)

Therefore VAM gas comprises a significant $1.5 \%$ of global anthropogenic greenhouse gas emissions; this is $630 \mathrm{Mt} \mathrm{CO} 2-\mathrm{e}$. At present, the technology to mitigate VAM cost-effectively, efficiently and safely is a work in progress (Baris, 2013). However, there is concern now over VAM fugitive greenhouse gas emissions, and that these need to be reduced. Of course, methane has been controlled in collieries for a long time, but this has always been for safety and statutory compliance reasons - not for environmental reasons. There has been some recent work to indirectly reduce VAM gas by using enhanced gas drainage methods (Packham et al., 2011). The aim of this work is to show how to prevent some methane, in a safe and cost-effective way, from entering the mine airstream and becoming fugitive VAM emissions. The climate change authority (2014) has outlined the possible range of VAM fugitive emissions from collieries in Australia to 2030 (Figure 5).

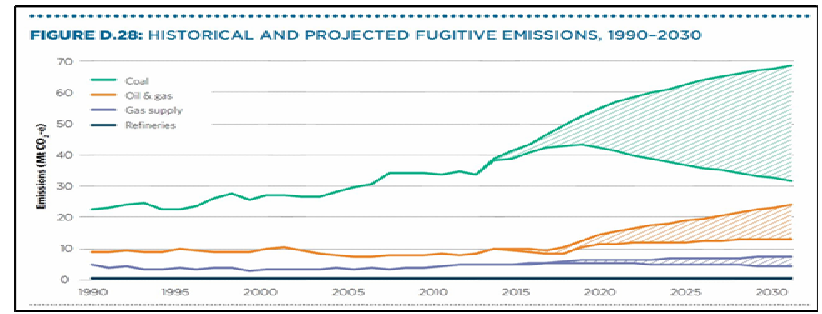

Figure 5. Fugitive emissions from Australian coal mines (Climate Change Authority, 2014)

VAM fugitive emissions from collieries in Australia currently (2016) represent $38 \mathrm{Mt} \mathrm{CO} 2-\mathrm{e}$ which is a significant $6.3 \%$ of Australia's total greenhouse gas emissions. An increase in VAM gas emissions is anticipated in all scenarios, because of projected increases in coal exports and the mining of lower, gassier seams. Around 2022 the use of VAM plants is expected to reduce this source of emissions. However, there are large uncertainties in the projected figures (Climate change authority report, 2014).

\subsection{VAM mitigation difficulties}

VAM emissions for the two largest emitters, China and the U.S. have been estimated by the USEPA (U.S. EPA) at 6.7 Billion $\mathrm{m}^{3}$ and 2.6 Billion $\mathrm{m}^{3}$, respectively. Australia's emissions in 2002 were estimated at 0.7 Billion $\mathrm{m}^{3}$ (Somers and Schultz, 2008). Commercial VAM treatment plants are becoming available, such as the VAM Thermal Oxidiser (VAMTOX). The first successful demonstration of a small scale VAM plant was in 1994 at Thoresby Mine in the UK, then later at Appin colliery and at West Cliff colliery in NSW, Australia. 
West Cliff VAM plant successfully generated 6MW of electrical power during operation. More recently a VAM pilot project, which handles $10 \mathrm{~m}^{3} / \mathrm{sec}$ has been undergoing operational testing at Mandalong colliery in NSW (Somers \& Schultz, 2008). Mandalong are planning to eventually fully treat all their VAM gas by using a thermal VAM plant; this would be a world first if it is achieved. To operate efficiently, VAM plants typically require at least a $0.8 \%$ methane concentration in the mine airflow; this often means that a supplemental source of methane needs to be added to the mine air flow to reach this level. An alternative would be to separate the long-wall return from the development return flows, and only treat the long-wall flow which is generally over $0.8 \%$. However, this has not been proposed or put into practice yet at any mine. Other stumbling blocks to this technology are safety issues, the very high cost of this form of mitigation and dirty mine air causing problems for the catalysts used in the oxidiser.

\subsection{MITIGATION AND MINE SAFETY}

The manner and amount in which fugitive greenhouse gases are mitigated depends to a large extent on how much they are taxed or how much is available for mitigation through schemes like direct action, and what mitigation is specifically covered by those schemes. VAM plant is covered; however there are serious safety concerns in underground coal when attempts are made to attach VAM gas plants to the main fans. Most VAM plants are basically a huge oven, which destroys methane by burning it at $1,000^{\circ} \mathrm{C}$ (Zhang et. al. 2014). The idea of connecting a VAM plant to a colliery is meeting stiff resistance from many coal mineworkers and managers. Even flaring drained methane has met resistance to date in the USA; a practice that is arguably safer than a VAM plant is perceived to be (Karacan et al. 2011). It is a fact that coal miners and coal mine managers are rightly cautious when it comes to safety, especially in regards to ignition sources. In Australia, smoking is not permitted anywhere on site, many items are classified as contraband and not permitted into the mine, such as cameras and phones, even an ordinary battery operated watch is banned.

VAM can be mitigated in another way, without using a VAM plant. The exhaust mine air can be used as feed air to a genset. This not only destroys the methane, but uses all of the feed VAM to generate power in the genset. In a world's first commercial use of VAM, the Appin colliery in NSW, Australia used $20 \%$ of its exhaust mine air to feed $54 \times 1 \mathrm{MW}$ gas gensets which it runs on site from its gas drainage system. This is estimated to add 4 to $8 \mathrm{MW}$ to the output of the gensets, resulting in an average power generation of $55.6 \mathrm{MW}$, which is on-sold to a utility (Su and Agnew, 2006). Because the feed air is not ignited until it is inside a genset cylinder, this method is seen as safer than some of the alternative methods of VAM gas destruction; however, some issues still remain. There must be no point at which exhaust mine air (which could contain a plug of flammable methane gas) might contact surfaces of high temperatures and ignite. Strict controls have to be enforced between the point where mine air exits the fans and the point where the high temperatures in the gensets exist. Using the dirty mine air as feedstock air for the gensets was discontinued at Appin due to the frequent cleaning required which caused cost inefficiencies for the operation (Limbri et al., 2013).
The concerns raised by connecting a VAM plant directly to the mine fans centre around the properties of methane gas, which is explosive in air when between $5 \%$ and $15 \%$ concentrations. If the mine were to expel a plug of methane through the fans at $5 \%+$ concentration, due to the failure of a seal or an outburst event for example, this could prove to be catastrophic. If ignited by the VAM plant, the flame would propagate all the way back through the mine to the source of the leak and could trigger a mine dust explosion. Hence the reticence of some mines managers to even consider the connection of a VAM plant. Occasionally, as here, the two aims of a requirement to not reduce mine safety levels and the need to mitigate emissions conflict. These conflicts should be identified and dealt with in any good, comprehensive risk assessment process. As always, the safety of the mineworkers must take precedence over any thought of mitigation of emission reductions.

This is where the six mitigation measures that were used in the 12-month Hunter Valley trial have the advantage over VAM destruction by heat; they are not only completely safe, but by their nature the application of any of them actually improves mine safety further. Concerns about these mitigation measures therefore will probably not come from the point of view of safety, but only from a cost perspective. It is expected that the cost of implementation will be wholly met by the clean energy regulator through a major project application to the direct action auction system.

\section{METHODOLOGY}

\section{The mitigation method involved these six measures;}

\subsection{Identify and stop seal leaks from seals}

Example: A small leak was discovered in an old seal; the leak was measured by surveying the roadway on either side of the seal for airflow and percentage of methane, and calculated to emit an average of $700 \mathrm{ml}$ per second of CH4. To simplify matters, no allowance is made in any calculation for pressure or CH4density changes due to movement of $\mathrm{CH} 4$ in a vertical direction, which in any case are small because of the shallow depth of the workings in question. Emissions in $\mathrm{CO} 2$-e are given by:

\section{Calculation a);}

Ideal CH4 Law; Density $=$ PM/RT

$\mathrm{P}=$ mine pressure $=0.978 \mathrm{~atm}$

$\mathrm{M}=$ molar mass $=16.042 \mathrm{~g} / \mathrm{mol}$

$\mathrm{R}=\mathrm{CH} 4$ constant $=0.82057 \mathrm{~L}$ atm $\mathrm{mol}^{\wedge}-1 \mathrm{~K}^{\wedge}-1$

$\mathrm{T}=$ mine temp in Kelvin $=298.15 \mathrm{~K}$

Global Warming Potential (GWP) from the IPCC's AR4 $=21$

Mine density methane $=0.978 \mathrm{~atm} \times 16.042 \mathrm{~g} / \mathrm{mol} /(0.082057$

Latmmol^-1K^-1 x $298.15 \mathrm{~K}$ ) $=0.641 \mathrm{gm} /$ litre

Litre $/ 700 \mathrm{ml}=1.4$

Leak is therefore 0.641 grams every 1.4 seconds

There are $31,550,000$ seconds in a year $/ 1.4=22,500,000$

$22,500,000 \times 0.641$ grams $=14.4$ tonnes $\mathrm{CH} 4$

$\mathrm{CH} 4$ make $\mathrm{x}$ GWP $=\mathrm{CO} 2$-e emissions

$14.4 \times 21=302.4$ tonnes $\mathrm{CO} 2$-e emissions/year

A small leak of this size is difficult to detect without regular and accurate measurements or leak tests taken very near the 
seal; these are not routinely done. The daily diurnal pressure changes also mean that the leak may often stop or even reverse, making it all but undetectable at those times. Leaks like this are very common in old seals around sealed up panels; and old sealed panels often have 50 or more seals. Finding and plugging this small leak is the equivalent in greenhouse emissions saved, to taking 60 cars off the road. The equivalent of 24 leaks of this size were detected in surveys, (totalling a VAM reduction of 16.8 litre/sec $\mathrm{CH} 4$ ) and all were quickly and satisfactorily plugged and sealed using portable silent seal products.

\section{Cost calculation;}

Deputy and ventilation officer's time 20 hours $\$ 2,000$

Mineworkers time applying product 15 hours $\quad \$ 1,000$

Silent seal x 2

$\underline{\$ 1,200}$

Total

$\$ 4,200$

\subsection{Seal off unused roadways in the mine}

The single-entry back road of the upper PG (Pikes Gully) seam was sealed up on the 29th September, 2012; because this $5 \mathrm{~km}$ of roadway was already planned to be sealed, the associated emissions savings were not counted as part of this study. However, other roadways were not planned to be sealed off in the normal course of events; main-gate 9 and the back road of LW8 (Figure 6).

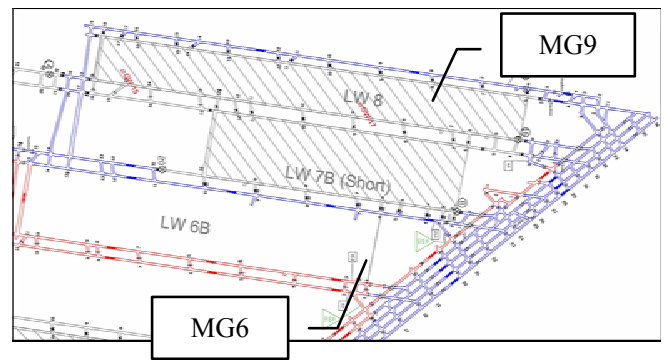

Figure 6. Hunter Valley colliery map detail of LW8 and LW7B

These roadways were known at the mine to be a particular source of methane leaks. This was due to;

- Old-style shotcrete seals, which were unsatisfactory

- Wooden cribs which shrink as they dry out, causing them to fail to support the roof properly

- Geotechnical issues caused by the narrow width of the MG9 pillars

- Spalling ribs in the various cut-throughs which caused leaks

Although there had been no plan to seal off these roadways, the cost of the above maintenance issues coupled with the related emissions costs incurred to the mine in terms of the thenexisting carbon price, made the decision to seal it off possible. Prior to the seal-up of MG9 and the back road of LW8, the airflow required to ventilate them was $29.5 \mathrm{~m}^{3} / \mathrm{sec}$; this was more than $10 \%$ of the entire mine airflow. Even then, the in-bye end of the roadway could exceed $1 \% \mathrm{CH} 4$ during rapid diurnal falls in atmospheric pressure, (this represents a $\mathrm{CH} 4$ make of 300 litres/sec) often occurring at $4 \mathrm{pm}$ and $4 \mathrm{am}$; thus preventing machinery access at those times (CMHSR, NSW 2006 and CMSHR QLD 2001).

Several spot $\mathrm{CH} 4$ measurements and surveys of the roadway were made by the deputies and the ventilation officer respectively, and the average intake and exit $\mathrm{CH} 4$ levels just prior to seal-up were determined to be;

Intake 5-6 c/t A heading, MG9 $\quad=0.05 \% \mathrm{CH} 4$

Backroad LW8 $\quad=0.50 \% \mathrm{CH} 4$

MG9 CH4 CH4 $\quad=0.45 \%$ of $29.5 \mathrm{~m}^{3} / \mathrm{sec}$

Average make $\mathrm{CH} 4 \quad=132.75$ litres $/ \mathrm{sec}$

Using above calculation a);

$0.641 \mathrm{gm} /$ litre x $132.75=85.1 \mathrm{gm} / \mathrm{sec}$

$31,550,000 \mathrm{sec} \times 85.1=2,684 \mathrm{t} \mathrm{CH} 4 /$ year

$2,684 \times 21 \mathrm{GWP} \quad=5.6378 \times 10^{4}$ tonnes $\mathrm{CO} 2$-e $/$ year

The annualised cost of these emissions to the mine at the time was $56,378 \times \$ 23=\$ 1,296,000$. A decision was made to seal these two roadways and to inertise them by using $\mathrm{CH} 4$ from the LW8 sealed goaf.

Calculated time to inertise the $1,800 \mathrm{~m}$ roadway;

Volume of roadway; $1,800 \mathrm{~m} \times 14.5=26,100 \mathrm{~m}^{3}$

$\mathrm{CH} 4$ required to inertise roadway; $26,100 \times 0.15=3,915 \mathrm{~m}^{3}$

Estimated $\mathrm{CH} 4$ make of MG9 seals; from 12 noon to $6 \mathrm{pm}=$ $>300$ litres/sec

Estimated time to reach $>15 \% \mathrm{CH} 4 ; 3,915 / 0.3=13,050 \mathrm{sec}(3.6$ hours)

- Sealing was undertaken on a falling barometer between $11 \mathrm{am}$ and $5 \mathrm{pm}$

- The out-bye end of MG9 will be on - ve $400 \mathrm{~Pa}$ return pressure causing the seals to breathe out

- LW8 contains 95\% methane; this will be used to inertise MG9 and the LW8 back road

- The 4" inertisation pipeline which passes through the seals will be opened on personnel exit

- Up to $20,000 \mathrm{~m}^{3}$ of methane will be stored in this roadway

- Approximate volume of methane in LW8 goaf is $150,000 \mathrm{~m}^{3}$

- This stored CH4 can be tapped from the surface and used for power generation at a later time

- The emissions saved are annualised for one year, even though these roadways in the normal course of events would have been in use for much longer.

Cost calculation;

Deputy and ventilation officer's time 100 hours $\$ 10,000$

Risk assessment $\$ \$ 12,000$

Seal-up doors x $2 \quad \$ 11,000$

Pipework and clearing roadway $\$ 20,000$

Ventilation change \& seal-up works $\$ 25,000$

Monitoring costs $\$ \$ 2,000$

Total $\$ \$ 80,000$

\subsection{Install 5psi stoppings in front of old 20psi seals}

To use the single-heading of MG6 as a long-wall main-gate intake and as a belt road, called for innovative thinking at the mine (Figure 6). This situation was brought about because of out-of-sequence panel mining, caused by delays in surface environmental works associated with the re-location of a creek. The installation of the extra 5psi stoppings was done along the single heading in MG6 to increase seal resistance enough to keep methane ingress from sealed panel LW7B into MG6 to within the statutory limit. Because this roadway was later to be the main-gate (intake) for the extraction of LW6B, these prevention works were important because the statutory limit is just $0.25 \%$ methane on long-wall intakes in NSW. Measurements of pressure and $\mathrm{CH} 4$ were done along MG6 and 
its seals associated with LW7B in order to quantify $\mathrm{CH} 4$ make and any likely problems which may occur due to this leakage into the main-gate during the extraction of LW6B.

The installation of 5psi mine plaster barrier stoppings in front of the existing 20psi seals was decided on in at a risk assessment for the mining of LW6B, in spite of the excellent condition of the seals. The decision was based on two factors, prudence; and the modelled and calculated extra leakage expected from these seals as they were put under more differential pressure due to the extra airflows needed for servicing a production main-gate. A further control would be a $0.25 \% \mathrm{CH} 4$ detector in the maingate, which would trip the power to the long-wall if exceeded. Other contingencies were planned for in the risk assessment, such as an application for an exemption to the $0.25 \%$ intake rule; it was hoped permission to allow $0.5 \%$ for this panel could be gained from the inspector. Other contingencies which were planned for were a provision to draw off the methane in between the barrier seals; pipework for this was to be preinstalled and excess $\mathrm{CH} 4$ was to be directed into the returns. However, it was hoped that in practice, neither of these contingencies would be required.

Pressure drop down MG6 now are given by:

Calculation b);

Find Atkinson's resistance of the current situation first, using;

$$
\text { Resistance }=\mathrm{KL} \text { Per } / \mathrm{A}^{3}
$$

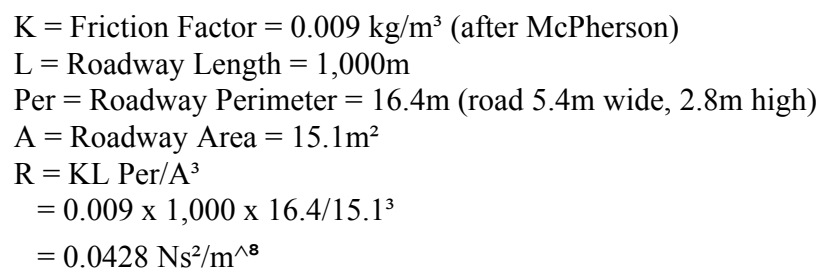

Find pressure drop, $\mathrm{P}$;

$$
\begin{aligned}
& =0.0428 \times 23.0^{2} \quad \mathrm{P}=\mathrm{RQ}^{2} \\
& =22.64 \mathrm{~Pa}
\end{aligned}
$$

Projected pressure drop down MG6 are given by;

\section{Calculation c);}

$\mathrm{K}=$ Friction Factor $=0.011 \mathrm{~kg} / \mathrm{m}^{3}$ (after McPherson)

$\mathrm{L}=$ Roadway Length $=1,000 \mathrm{~m}$ (at start)

Per $=$ Roadway Perimeter $=16.4 \mathrm{~m}(\operatorname{road} 5.4 \mathrm{~m}$ wide, $2.8 \mathrm{~m}$ high)

$\mathrm{A}=$ Roadway Area $=15.1 \mathrm{~m}^{2}$

$$
\mathrm{R}=\mathrm{KL} \text { Per } / \mathrm{A}^{3}
$$

$$
\begin{aligned}
& =0.011 \times 1,000 \times 16.4 / 15.1^{3} \\
& =0.0524 \mathrm{Ns}^{2} / \mathrm{m}^{\wedge 8}
\end{aligned}
$$

Find pressure drop, P;

$$
\begin{aligned}
& =0.0524 \times 60.0^{2} \quad \mathrm{P}=\mathrm{RQ}^{2} \\
& =188.64 \mathrm{~Pa}
\end{aligned}
$$

Airflows along MG6 were expected to rise from the current $23.0 \mathrm{~m}^{3} / \mathrm{sec}$ to $60.0 \mathrm{~m}^{3} / \mathrm{sec}$ during production; a conveyor belt is also to be installed in MG6; because of this, vehicle access is to be largely via $B$ heading in the tailgate. The pressure drop down the length of the roadway was calculated to increase from 22.64 $\mathrm{Pa}$ to188.64 $\mathrm{Pa}$. This would increase the pressure differential down the length of sealed panel 7B by the difference between $2 / 3$ rds of these numbers (given that panel $7 \mathrm{~B}$ is two-thirds the length of MG6). This increase in differential pressure along the length of the sealed goaf 7B, can then be quantified as;

$$
\begin{array}{ll}
2 / 3 \text { rds of } 22.6 \mathrm{~Pa} & =14.9 \mathrm{~Pa} \text { and } \\
2 / 3 \text { rds of } 188.6 \mathrm{~Pa} & =124.5 \mathrm{~Pa} \text { respectively. }
\end{array}
$$

The pressure differential along the sealed panel length therefore is projected to increase substantially from a negligible $14.9 \mathrm{~Pa}$ to $124.5 \mathrm{~Pa}$. This would be expected to cause the in-bye seals to leak more by adding to the already substantial (approx. \pm 150 $\mathrm{Pa}$ ) diurnal changes during their median daily lows at around $4 \mathrm{pm}$ and $4 \mathrm{am}$. The average diurnal change of $\pm 150 \mathrm{~Pa}$, added to the pressure fall during production along the length of the sealed panel would be $124.4+150 \mathrm{~Pa}=274.4 \mathrm{~Pa}$.

However, since any passing storm will cause a barometer fall in excess of the average diurnal change, prudence in planning demands that we use a factor of safety here before we use any pressure level in our calculations in the determination of the seal resistance which we require to prevent excessive $\mathrm{CH} 4$ leakage into MG6. Because of the very real concern over the potentially high costs associated with any productions shutdown due to $\mathrm{CH} 4$ ingress, a factor of safety of 1.5 was decided on, hence a maximum differential of; $274.4 \times 1.5=412$ $\mathrm{Pa}$ was to be used in the $\mathrm{CH} 4$ flow calculations.

Calculation d);

Flow $\quad=60 \mathrm{~m}^{3} / \mathrm{sec}$

Max CH4 concentration allowed $\quad=0.25 \%$

$\mathrm{CH} 4$ concentration on panel intake measured at $=0.05 \%$

Leakage allowed is therefore $\quad=0.20 \%$ $=60 \times 0.002=0.12$

Allow for the CH4 concentration being $90 \%=0.14 \mathrm{~m}^{3} / \mathrm{sec}$

At LW6 start-up, nine seals in MG6 would need to be included in our calculations (In B hdg; 3c/t, 4c/t, 5c/t, 6c/t, 7c/t, 8c/t, $9 \mathrm{c} / \mathrm{t}, 10 \mathrm{c} / \mathrm{t}$ and in A hdg $10-11 \mathrm{c} / \mathrm{t}$ ).

Since; $\quad \mathrm{Rt}=\mathrm{P} / \mathrm{Q}^{2}$

$\begin{array}{ll}\text { Then; } & =412 / 0.14^{2} \\ \text { Total resistance; } & =21,000 \mathrm{Ns}^{2} / \mathrm{m}^{-8}\end{array}$

Since; $1 / \sqrt{ } \mathrm{Rt}=1 / \sqrt{ }(\mathrm{R} 3 \mathrm{c} / \mathrm{t})+1 / \sqrt{ }(\mathrm{R} 4 \mathrm{c} / \mathrm{t}) \ldots . .1 / \sqrt{ }(\mathrm{R} 10-11 \mathrm{c} / \mathrm{t})$

And if; $R 3 c / t=R 4 c / t=R 5 c / t=R 6 c / t=R 7 c / t=R 8 c / t=R 9 c / t=$

$\mathrm{R} 10 \mathrm{c} / \mathrm{t}=\mathrm{R} 10-11 \mathrm{c} / \mathrm{t}$

Then; $\quad 1 / \sqrt{ } \mathrm{Rt}=1 / \sqrt{ } 21,000=0.0069$

And; $\quad 0.00077=1 / \sqrt{(\mathrm{R} \text { any seal })}$

Then; $R$ any seal $=1.68 \times 10^{6} \quad \mathrm{Ns}^{2} / \mathrm{m}^{-8}$

The seals in each cut-through therefore need to achieve a resistance of 1.7 million gauls to satisfy our $\mathrm{CH} 4$ leakage restrictions into MG6. This proved to be achievable; each 20 psi seal was sprayed over again, and up to $4 \mathrm{~m}$ of rib and roof was also sprayed to a depth of $50 \mathrm{~mm}$. Then a second barrier seal of 5 psi rating was installed $4 \mathrm{~m}$ in front of that seal, and again, the roof and ribs sprayed out to $4 \mathrm{~m}$ and to a $50 \mathrm{~mm}$ depth. Tube bundle and local monitoring pipes were installed, along 
with a $200 \mathrm{~mm} \mathrm{CH} 4$ drainage line through each 5psi stopping, and running to the main returns. The $\mathrm{CH} 4$ drainage line was to be used in the unlikely event that leakage through the seals into MG6 caused production stoppages.

The installation of the 5psi stoppings and the over-spraying resulted in some $\mathrm{CH} 4$ leak reductions during the time-frame of this study, however most of the savings would have occurred after this study ended in June, 2013; the reason is because the projected increase in airflow and hence the higher pressure differential did not happen until after that. Therefore an estimated pro-rata emissions savings and costs have been applied in this case.

Cost calculation;

Deputy and ventilation officer's time 10 hours

$\$ 1,000$

5 psi seal installation (part cost)

$\$ 4,000$

Total

$\$ 5,000$

\subsection{Change seal design from shotcrete to mine plaster}

Old-style 20psi shotcrete seals were being installed at the mine. These were found to be unsatisfactory form several points of view;

- Frequent became leaky when roof, ribs or floor moved because of their rigidity and so required constant maintenance

- Many leaks appearing on the roof-line or under through-seal pipework due to slumping of the concrete on installation adding to VAM gas and emissions

- Costly and time-consuming to install

- No new-seal specific documented inspections carried out after installation

- Single-tube roof monitoring arrangement unsatisfactory

- 20 psi seal made of different materials to 5psi stoppings, requiring separate stocks of materials

- Issues with safety because of the design re; materials handling

- Long-time of installation causing unnecessary risks to workers i.e.; exposure to goaf and its Gases

- Use of outdated wooden cribs, issues are; flammable materials, slow installation, materials handling issues, lack of ability to create rapid and positive roof support when needed, wood shrinkage issues causing failure to support roof over time, lack of continuous support causing rib spalling and leaks

A new seal design was implemented. The new seals are 20 psi and made from high strength water resistant mine plaster (HSWR). The old wooden cribs were replaced by quick to install adjustable 40 tonne roc-props. The single roof-top copper sample pipe was replaced with $3 \mathrm{x}$ pvc sample tubes, set at different heights behind the seal; the "traffic light" standard of red, yellow and green sample tubes. A new seal inspection regimen was implemented to assess and record the installation standard. The HSWR mine plaster seals were superior in almost every respect to the old shotcrete/single sample point/wooden crib arrangement which was in place. However, we will concentrate on their benefits with regard to prevention of methane leaks, both immediately on installation and longer term.
The old seals would commonly have leaks straight after installation, typically of 5-10 millilitres/sec. With time, the cribs would shrink and fail to support the roof both behind the seal and in front of it. The concrete would flake and decay, the bottom became affected by standing water; the roofline would separate from the seal top, movement in the ribs would cause spalling and more leaks. Constant inspections and repair works were necessary. Due to constraints on the deputy's time, often only the leakiest seals were noted and attended to. Detection of lesser problems and action on them was often left to the ventilation officer, working with one of the out-bye undermanager's. Costs here were minimal; in fact the new seal standard saved the mine money.

Quantifying the effect on VAM of the switch to HSWR seals is tricky, because due to the expense, they were installed only as required during the normal running of the mine, and were not primarily installed for the specific purpose of controlling emissions. Their superior resilience, rapidity of installation, flexibility, lack of slumping, resistance to mine water and use of positive support like roc-props instead of cribs, all conspired to reduce both their initial production of VAM, and their production of this fugitive emission over time. These new seals are being installed at the rate of approximately 25 per panel, and one panel is mined on average every year. If we assume the lowest likely average leak difference of 50 millilitres/sec, then the emissions saved after 1 year of steady replacement of the old leaky seals would be;

\section{Calculation e);}

$50 \times 25 \times 0.5 \times 3.15 \times 10^{7}=1.9 \times 10^{7} \quad$ litres saved

If we take the density of methane from calculation a above, $=$ 0.641 grams/litre, then;

Savings: $0.641 \times 1.97 \times 10^{7}=1.264 \times 10^{7}$ grams

GWP

$$
=12.64 \mathrm{t} \mathrm{CH} 4 \times 21
$$

$$
=265.44 \text { tonnes } \mathrm{CO} 2-\mathrm{e} / \text { year }
$$

Because the switch to a new seal design was not primarily done to reduce emissions, only a small part of any possible changeover cost is allowed here. In fact, a subsequent cost-benefit analysis has shown that the change-over to new seals had no net cost, and was revenue positive.

Cost calculation;

Deputy and ventilation officer's time (part cost) $\$ \$ 500$

Engineer's design drawings (part cost) $\$ \$ 500$

Total $\$ 1,000$

\subsection{Reduce leaks from goafs by pressure balancing panels}

Leaks from old sealed panels in a long-wall coal mine still happen, even after the above strict regimen has been followed; i.e. fix leaky seals, seal off unused roadways, install barrier seals and switch to new and better seals. These leaks can be because of a combination of; the way the ventilation is arranged, and the diurnal change in atmospheric pressure. We can do something about this the ventilation arrangements.

A sealed panel, if not pressure balanced, will leak $\mathrm{CH} 4$ out of one side, and leak mine air into the other side. This is most undesirable in three ways; 
1) More VAM gas is created than needs to be, causing more fugitive emissions and also potential access issues due to gas in the returns during storms or common diurnal pressure falls.

2) Mine air leaks into sealed areas are to be avoided if possible, due to spontaneous combustion and explosive atmosphere risks.

3) Efforts to prevent the ingress of mine air into the sealed area, and efforts to prevent gas from leaking out of the sealed area cost time and money.

Even so, sealed panels which are not pressure balanced are common in underground coal mines in Australia. In the example here (Figure 5) the sealed panels LW8 and LW7B were calculated to have combined due to the strong likelihood of some of the seals between them collapsing during the mining of LW8, in particular 8c/t and $9 \mathrm{c} / \mathrm{t}$, MG8. They can therefore be treated as a single sealed panel for pressure balancing purposes. Given that LW6B was still to be mined, and that it would be undesirable to have the seals in MG6 leaking excessively when put under a potential pressure drop of $412 \mathrm{~Pa}$ (as calculated in c above) not only from the point of view of the continuity of production, but from an emissions standpoint, it was decided to induce a negative pressure gradient across from MG6 to MG9.

To enable this, the correct course of action was decided from modelling to put MG9 on full return pressure to pull back the goaf gases in the combined panel away from the MG6 seals as much as possible to prevent $\mathrm{CH} 4$ ingress into the LW6B maingate. To this end, a ventilation change was made, which removed all regulation in the $\mathrm{PG}$ mains returns in $\mathrm{A}$ or $\mathrm{B}$ heading and introduced regulation in the form of mine doors in A heading, MG9 4-5 c/t. Regulation started across the doors at $475 \mathrm{~Pa}$ and in succeeding months varied up to $910 \mathrm{~Pa}$ as production moved from the ULD to the mining of LW6B in the PG seam; the MG9 seals were basically kept on the existing full return pressure for months before, and throughout the mining of LW6B.

After mining of LW6B commenced, this had the effect of helping to prevent excessive $\mathrm{CH} 4$ movement across from the combined panel into the new LW6B goaf, as it was expected from a geotechnical study that one or two seals in MG6 would probably collapse after the long-wall passed them. The prevention of sudden movements of high-percentage stored methane gas was always a part of the ventilation planning process. From tube bundle monitoring, the combined panel was known to contain approx. $90 \%$ methane, therefore it was not possible to increase the methane content in this goaf very much. However, it was possible to do this in other panels, such as the sealed goaf of LW1 in the PG seam; this additional stored $\mathrm{CH} 4$ (by increasing $\mathrm{CH} 4$ concentration in a previously sealed goaf) will be quantified next. However, the initial effect of putting MG9 on full return pressure was to create a pressure balance across the sealed panels and so prevent leakage through seals on all sides of the sealed panel. This reduced the creation of VAM gas. Gas surveys were taken to quantify this saving in emissions due to the pressure balancing across the sealed panel LW8 and LW7B details of this measure is described as follows;

\begin{tabular}{|l|l|}
\hline \multicolumn{1}{|c|}{ Place measured } & \multicolumn{1}{c|}{$\begin{array}{c}\text { CH4 general body; 10m out-bye of the } \\
\text { most in-bye seal noted }\end{array}$} \\
\hline MG6 A hdg 3-4 c/t & 0.05 \\
\hline MG6 A hdg 4-5 c/t & 0.08 \\
\hline MG6 A hdg 5-6 c/t & 0.12 \\
\hline MG6 A hdg 6-7 c/t & 0.15 \\
\hline MG6 A hdg 7-8 c/t & 0.20 \\
\hline MG6 A hdg 8-9 c/t & 0.22 \\
\hline MG6 A hdg 9-10 c/t & 0.25 \\
\hline MG6 A hdg 10-11 c/t & 0.30 \\
\hline Total gas make is: & $0.25 \%$ of general body flow \\
\hline
\end{tabular}

Table 7. Measurements of $\mathrm{CH} 4$ concentrations in MG6 from a gas survey on $14 / 11 / 12$

As we noted in section 2.3, we need to achieve a resistance of 1.7 million gauls in the seals along MG6 in order to satisfy our $\mathrm{CH} 4$ leakage restrictions into MG6. We are now in a position to be able to calculate the resistance of these seals prior to the ventilation change to triple the airflow down MG6. This assists us with planning the fine detail of the ventilation arrangements for the mining of LW6B.

\section{Calculation f);}

Measured airflow in MG6, A hdg intake, $4-5 \mathrm{c} / \mathrm{t}: 28.4 \mathrm{~m}^{3} / \mathrm{sec}$ Average make CH4 28.4 x $0.25 \%=71$ litre $/ \mathrm{sec}$

Assume all 8 seals involved have the same resistance.

Average seal leakage is approximately; $71 / 8=8.87$ litre/sec

Measured seal pressures during the gas survey are; across $4 \mathrm{c} / \mathrm{t}$ seal $+200 \mathrm{~Pa}$ and across the $10 \mathrm{c} / \mathrm{t}$ seal $+240 \mathrm{~Pa}$ therefore MG6 seals are all breathing out (gas survey was deliberately carried out during a diurnal fall in the barometer). The average seal pressure is taken to be $+220 \mathrm{~Pa}$.

Find the resistance of the individual seals.

Since; $\quad \mathrm{R}=\mathrm{P} / \mathrm{Q}^{2}$

$$
\begin{aligned}
& =220 / 0.00887^{2} \\
& =2.8 \times 10^{6} \mathrm{Ns}^{2} / \mathrm{m}^{-8} \\
& =2.8 \text { million gauls }
\end{aligned}
$$

This gas survey confirms that the seal over-spraying, installation of a second $5 \mathrm{psi}$ barrier seal and roof and rib spraying has worked and we have easily reached our seal target resistance of $1.68 \times 10^{6} \mathrm{Ns}^{2} / \mathrm{m}^{-8}$.

Average gas make MG6 before pressure balancing (from ventilation measurements) $=82.9$ litres $/ \mathrm{sec}$

Average gas make MG6 after pressure balancing (from ventilation measurements) $\quad=51.1$ litres $/ \mathrm{sec}$

Measured mitigation from pressure balancing the sealed panels LW8 and LW7B $=31.8$ litres $/ \mathrm{sec}$

\section{Calculation g);}

$0.641 \mathrm{gm} /$ litres x $31.8=20.38 \mathrm{gm} / \mathrm{sec}$

$31,550,000 \sec \times 20.38=643 \mathrm{tCH} 4 /$ year

$643 \times 21$ GWP

$=1.35 \times 10^{4}$ tonnes $\mathrm{CO} 2$-e $/$ year

Cost calculation;

Deputy and ventilation officer's time 50 hours $\quad \$ 5,000$

Ventilation change

$\$ 2,000$

Total

$\$ 7,000$ 


\subsection{Use pressure differential to move methane to goaf voids}

As noted above in method 2, we saw that $20,000 \mathrm{~m}^{3}$ of methane was stored in MG9 and the LW8 back roadway. Another panel where pressure differentials were used to move $\mathrm{CH} 4$ is when the LW101 panel was being mined in the Upper Liddell seam (ULD) which is a lower seam to the PG, being 40metres lower. In this case, the $\mathrm{CH} 4$ was moved by putting the sealed panel LW1 of the PG seam on full return pressure, through its accessible seals. This amounted to a pressure differential of 250 $\mathrm{Pa}$ when compared to the centre of the long-wall of the LW101 panel at start-up and increasing to $515 \mathrm{~Pa}$ at the $2 / 3 \mathrm{rd}$ mined stage.

Another reason this was done was to prevent $\mathrm{CO} 2$ from coming down onto the long-wall from the old LW1 goaf and causing the statutory $\mathrm{CO} 2$ level of $1.25 \%$ in working areas from being exceeded. The CO2 levels were known to be $9 \%-22 \%$ in the old LW1 goaf from tube bundle monitoring; the $\mathrm{CH} 4$ levels were also known to be $5 \%-10 \%$ with negligible levels of $\mathrm{O} 2$. The plan was to keep this overlying goaf inert right through the extraction of the LW101 panel by causing much of the methane released during the mining to flow upwards using a sufficient pressure differential. The $\mathrm{O} 2$ was kept low by a strong regimen of surface remediation works, which involved using a dozer over the subsidence-induced surface cracks to rip and then compact the surface wherever cracks were seen.

Excessive $\mathrm{O} 2$ was prevented from flowing upwards from the long-wall by a 'loop' of pressure from the main-gate to the tailgate; causing the majority of ventilation air to descend down into the tail-gate returns. Other active $\mathrm{CH} 4$ controls were a tight brattice barrier across the main-gate, level with the chocks, a tail-gate brattice barrier and a close back-road bleed to pull $\mathrm{CH} 4$ away from the tail-gate machinery. The mining of LW101 was preceded by extensive modelling, monitoring and calculations to ensure that $\mathrm{CH} 4$ movements were not going to be adverse when the panel was mined. One aim was to ensure that as much $\mathrm{CH} 4$ as possible was left in the combined goafs after LW101 was completed and sealed. This was achieved through buoyancy pressure and differential mine pressure brought about through the ventilation arrangements. $\mathrm{CH} 4$ production from the long-wall which was excessive was drawn off by a surface goaf $\mathrm{CH} 4$ drainage plant, which operated through pre-drilled vertical holes at a spacing of $500 \mathrm{~m}$, centred on the panel and ending $17 \mathrm{~m}$ above the PG seam. The concentration of $\mathrm{CH} 4$ in the LW1 panel was monitored by three pre-existing tube bundle points, and increased from $6 \%$ to $30 \%$ during the period 20th Sept - 1st Nov 2012. Concentrations of $\mathrm{CO} 2$ and $\mathrm{O} 2$ remained fairly steady. By the completion of the entire LW101 panel, the CH4 concentration had lifted to $65 \%$ in the LW1 PG (the upper seam) goaf. To ascertain the amount of extra CH4 being stored, we need to ignore the lower LW101 panel goaf, and count the extra CH4 stored only in the LW1 PG goaf. The costs involved in this storage were minimal, since the main expense was a limited amount of the ventilation officer's time for ventilation modelling. Surface remediation costs were not included, since they would have happened anyway due to spontaneous combustion and explosive atmosphere concerns.

\section{Calculation $h$ )}

Table 8. Cost-Benefit Analysis of all six measures
LW1

Total

$$
\begin{aligned}
& =1 / 2 \times 1,980 \times 2.5 \times 210=208,162 \mathrm{~m}^{3} \\
& =208,162 \mathrm{~m}^{3}
\end{aligned}
$$

$\mathrm{CH} 4$ increases from an average of $7.5 \%$ to an average of $65 \%$. Pre-existing CH4 stored $=7.5 \%$ of $208,162=13,530 \mathrm{~m}^{3}$ New storage amount $\quad=65 \%$ of $208,162 \mathrm{~m}^{3}=135,305 \mathrm{~m}^{3}$ Extra amount stored $\quad=135,305-13,530=121,775 \mathrm{~m}^{3}$

To this, we can add the $20,000 \mathrm{~m}^{3}$ which was stored in the unplanned seal-up of MG9 and the LW8 back road;
Total stored
$=141,775 \mathrm{~m}^{3}$

From calculation a, the density of methane under the specified conditions is 0.641 grams/litre or $0.641 \mathrm{~kg} / \mathrm{m}^{3}$

Therefore the total extra $\mathrm{CH} 4$ stored in these two voids is equal to a $\mathrm{CO} 2$-e of;
$141,775 \times 0.641 \mathrm{~kg}$
$=90.88$ tonnes $\mathrm{CH} 4$
CO2-e is; $90.88 \times 21$
$=1,908$ tonnes $\mathrm{CO} 2-\mathrm{e}$

Cost calculation;

Ventilation officer's modelling time 35 hours $\$ 3,500$

Ventilation changes costs $\$ \$ 2,500$

Total $\$ \$ 6,000$

Abatement calculated to be achieved in the period August 2012 to June 2013 (in tonnes CO2-e) using the six different measures were;

\begin{tabular}{lr} 
1) & 7,256 \\
2) & 56,378 \\
3) & 1,000 \\
4) & 265 \\
5) & 13,500 \\
6) & 1,908 \\
\hline Total: & 80,307 t/CO2- e abated
\end{tabular}

Table 8 and table 9 detail a cost-benefit of the mitigation and the VAM abatement achieved respectively. Figure 10 is a direct measure of the PG VAM gas make changes over the trial period. The total abatement achieved, $80,307 \mathrm{t} \mathrm{CO} 2-\mathrm{e}$ is equal to taking 17,000 cars off the road (EPA Australia, 2015).

\begin{tabular}{|l|c|c|c|c|}
\hline $\begin{array}{c}\text { VAM } \\
\text { mitigation } \\
\text { method }\end{array}$ & Cost $\$$ & $\begin{array}{c}\text { CO2-e } \\
\text { t/yr }\end{array}$ & $\begin{array}{c}\text { Mitigation } \\
\text { cost } \\
\$ / C O 2-\mathrm{e} / \mathrm{t}\end{array}$ & $\begin{array}{c}\text { If emitted; } \\
\text { cost } \$ 23 / \mathrm{t} / \mathrm{y}\end{array}$ \\
\hline $\begin{array}{l}\text { Stop } \\
\text { leaking } \\
\text { seals }\end{array}$ & 4,200 & 7,256 & 0.58 & 166,888 \\
\hline $\begin{array}{l}\text { Seal off } \\
\text { roadway }\end{array}$ & 80,000 & 56,378 & 1.42 & $1,296,694$ \\
\hline $\begin{array}{l}\text { Install 5psi } \\
\text { stoppings }\end{array}$ & 5,000 & 1,000 & 5.00 & 23,000 \\
\hline $\begin{array}{l}\text { Change } \\
\text { seal design }\end{array}$ & 1,000 & 265 & 3.77 & 6,095 \\
\hline $\begin{array}{l}\text { Pressure } \\
\text { balancing } \\
\text { panel }\end{array}$ & 7,000 & 13,500 & 0.52 & 310,500 \\
\hline $\begin{array}{l}\text { Increase } \\
\text { CH4\% old } \\
\text { goafs }\end{array}$ & 6,000 & 1,908 & 3.14 & 43,884 \\
\hline Totals & $\$ 103,200$ & 80,307 & $\begin{array}{c}\text { Ave mitigation } \\
\text { cost/t } \$ 1.28\end{array}$ & $\begin{array}{c}\text { If emitted } \\
\$ 1,847,061 / \mathrm{y}\end{array}$ \\
\hline & & $\begin{array}{c}\text { Net saving on } \\
\text { carbon price }\end{array}$ & $\$ 1,743,861$ \\
\hline
\end{tabular}

Volume of LW1 goaf $\quad=1 / 2$ volume of removed coal 


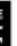
DE GRUYTER

\begin{tabular}{|l|c|}
\hline Methodology & VAM abatement achieved in litres/sec; \\
\hline 1 & 16.8 \\
\hline 2 & 132.8 \\
\hline 3 & 2.5 \\
\hline 4 & 0.6 \\
\hline 5 & 31.8 \\
\hline 6 & 4.4 \\
\hline Cumulative total & 188.9 litres/sec \\
\hline
\end{tabular}

Table 9. VAM abatement achieved in litre/sec for each measure

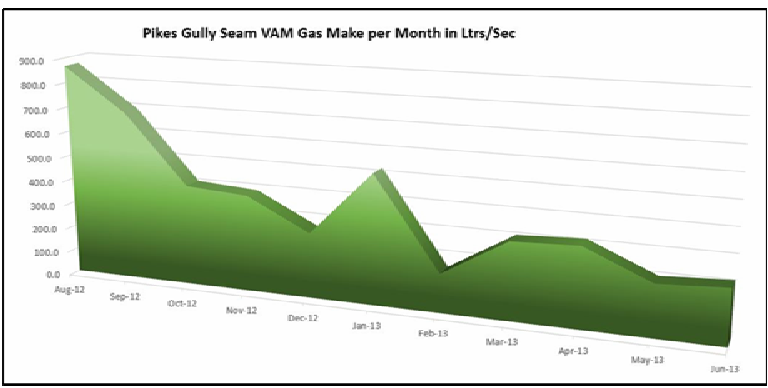

Figure $10 . \mathrm{VAM}^{*}$ as measured in the main return of the $\mathrm{PG}$ seam during the 12-month trial period

*note; not all the reduction in VAM gas seen here is due to the mitigation trial

\section{GOVERNMENT INCENTIVES TO ENCOURAGE} ABATEMENT

\subsection{Direct Action}

The current Australian government is using a different means of greenhouse gas reduction to the previous government's carbon price. Under 'direct action' the government buys carbon abatement in auctions through the clean energy regulator. The first auction of emission reductions was completed in April 2015 , at an average abatement price of $\$ 13.95 \mathrm{t} / \mathrm{CO} 2-\mathrm{e}$ (Australian Clean Energy Regulator, 2015). Collieries do qualify for abatement under direct action because they are almost all registered as large emitters under NGERS (National Greenhouse and Energy Reporting System).

\section{METHOD MAY BE EXTENDED}

\subsection{Other Australian collieries}

The mitigation method that consists of six measures (all of which are detailed here) and which underwent a 12-month trial in the Hunter Valley, is applicable to most collieries in Australia; and if it were to be extended to all Australia's 30 collieries, VAM gas emissions reductions amounting to at least three million tonnes of $\mathrm{CO} 2$-e per year should be possible. The method has three great advantages over other mitigation methods in collieries; these are that this type of mitigation is achievable at a very low cost, complicated expensive equipment is not needed and implementation also actually increases mine safety. In fact all six measures used in the 12-month trial individually enhance mine safety. However, when compared to mitigation or abatement of greenhouse gases in other areas of industry, the great advantage of this method is the very low cost of mitigation, which means in effect that far more emissions can be cut for the same dollar investment.

\section{CONCLUSION}

Planning for the control of fugitive greenhouse gas emissions such as VAM gas from a coal mine were not even considered until very recently. The new paradigm of a possible or an actual imposed cost (dollar cost or a reputation cost) or a possible financial benefit (for example; direct action mitigation) in relation to fugitive emissions means that greater consideration needs to be given to ventilation planning in certain specific areas. One solution would be a method to prevent more methane from entering the mine airstream and becoming VAM in the first place. The mitigation measure outlined herein represent a first attempt to the author's knowledge, in an operating mine, to lower a collieries' environmental footprint by preventing methane from entering the mine airstream and becoming VAM gas by the deliberate use of a mitigation measure. Recently, in a colliery in the Hunter Valley, this mitigation method underwent a 12-month trial, and involved six different measures.

Measurements were taken to assess the emissions mitigation which was achieved and the cost of the works; all the results of the trial are detailed here. A reduction in fugitive emissions of $80,307 \mathrm{t} / \mathrm{CO} 2-\mathrm{e}$ below that which was projected for the next $12-$ month period was quantified, at a total cost of $\mathrm{A} \$ 103,200$ which represents an average mitigation cost of $\mathrm{A} \$ 1.28 \mathrm{ct} / \mathrm{CO} 2-\mathrm{e}$. This mitigation cost is both well below the old carbon pricing mechanism, the prevailing low carbon price in Europe or the current Australian government's emission reduction fund's average price of $\$ 13.95 \mathrm{t} / \mathrm{CO} 2$-e from its first auctions in April and November of 2015, under its direct action plan through the clean energy regulator. It is also two orders of magnitude lower than the mitigation cost of large scale wind or rooftop solar photo-voltaic. The mitigation method in this study is applicable to most collieries in Australia; and if it were to be extended to all Australia's 30 collieries, VAM gas emissions reductions amounting to at least three million tonnes of CO2-e per year should be possible. The great advantages of this method is that this would be achievable at a very low cost when compared to mitigation in other areas of the economy, complicated machinery is not required to achieve it, and safety is not compromised; in fact all measures used as part of this method actually enhance mine safety.

\section{REFERENCES}

Australian Clean Energy Regulator: http://www.cleanenergyregulator.gov.au/ERF/Published-information/ auction-results/auction-results-april-2015.

Baris, K. (2013). Assessing ventilation air methane (VAM) mitigation and utilization opportunities: A case study at Kozlu Mine, Turkey. Energy for Sustainable Development, 17(1), 1323.

Climatechangeauthority.gov.au/reviews/targets-and-progressreview-3 (2014). 
西 DEGRUYTER

Crowley, T. J., \& North, G. R. (1988). Abrupt climate change and extinction events in earth history. Science, 240(4855), 9961002.

CMHSR; Coal mine health and safety regulation (2006).

(NSW) and the coal mining safety and health regulation. (2001) (QLD).

EPA, Environmental Protection Authority Australia (2015); average car emits 4.7t $\mathrm{CO} 2-\mathrm{e} / \mathrm{yr}^{-1}$ http://www.epa.gov/ otaq/climate/documents/420f14040a.pdf.

IPCC; https://www.ipcc.ch/.

IPCC; AR5 Report, 2014; https://www.ipcc.ch/report/ar5/.

Karacan, C. Ö., Ruiz, F. A., Cotè, M., \& Phipps, S. (2011). Coal mine methane: A review of capture and utilization practices with benefits to mining safety and to greenhouse gas reduction. International journal of coal geology, 86(2), 121-156.

Karakurt, I., Aydin, G., \& Aydiner, K. (2011). Mine ventilation air methane as a sustainable energy source. Renewable and Sustainable Energy Reviews, 15(2), 1042-1049.

Kissell, F. N. (2006). Handbook for Methane Control in Mining.

Limbri, H., Gunawan, C., Rosche, B., \& Scott, J. (2013). Challenges to developing methane biofiltration for coal mine ventilation air: a review. Water, Air, \& Soil Pollution, 224(6), $1-15$.

McPherson (2009). Subsurface ventilation engineering, chapter 12.

Myhre \& Shindell (2015). Anthropogenic and natural radiative forcing; WG1, AR5 report by the IPCC.

Packham, R., Cinar, Y., \& Moreby, R. (2011). Simulation of an enhanced gas recovery field trial for coal mine gas management. International journal of coal geology, 85(3), 247256.

Saghafi, A., Williams, D. J., \& Lama, R. D. (1997), Worldwide methane emissions from underground coal mining. In Proceedings of the 6th International Mine Ventilation Congress (pp. 441-445).

Sly, L. I., Bryant, L. J., Cox, J. M., \& Anderson, J. M. (1993). Development of a biofilter for the removal of methane from coal mine ventilation atmospheres. Applied Microbiology and Biotechnology, 39(3), 400-404.

Somers, J., \& Schultz, H. (2008). Thermal oxidation of coal mine ventilation air methane. Proceedings of the $12^{\text {th }} \mathrm{US} /$ North American mine ventilation symposium.

Su, S., \& Agnew, J. (2006). Catalytic combustion of coal mine ventilation air methane. Fuel, 85(9), 1201-1210.
Su, S., Beath, A., Guo, H., \& Mallett, C. (2005). An assessment of mine methane mitigation and utilisation technologies. Progress in energy and combustion science, 31(2), 123-170.

U.S. EPA; Coalbed Methane Outreach Program; http://www3.epa.gov/cmop/faq.html

Zhang, Y., Doroodchi, E., \& Moghtaderi, B. (2014). Chemical looping combustion of ultra low concentration of methane with Fe 2 O 3/Al 2 O 3 and $\mathrm{CuO} / \mathrm{SiO} 2$. Applied Energy, 113, 19161923.

Zhao, Y., Jiang, C., \& Chu, W. (2012). Methane adsorption behaviour on coal having different pore structures. International Journal of Mining Science and Technology, 22(6), 757-761. 